\title{
Harvest control rules in the context of fishery-independent management of fish stocks
}

\author{
Panayiota Apostolaki ${ }^{1, a}$ and Richard Hillary ${ }^{2}$ \\ ${ }^{1}$ CEFAS Lowestoft Lab, Pakefield Road, Suffolk, NR33 OHT, UK \\ 2 Division of Biology, Imperial College, London SW7 2AZ, UK
}

Received 5 August 2008; Accepted 9 April 2009

\begin{abstract}
Consideration of control rules as part of fisheries management plans is becoming a common practice. Control rules may be simple or complex and utilise model- or observation-based indicators of the status of the stock to control exploitation through limitation of effort or catches. Rules that control harvest (HCR) often utilize commercial fishery data in the calculation of future catches. However, commercial fishery data may be inaccurate and that can compromise the effectiveness of the HCR in maintaining the stock for secure future harvesting. The idea of fisheryindependent HCR has arisen because of these problems. Indicators of the status of a stock are derived from standardised fish surveys, commonly trawl surveys repeated annually. A management strategy that relies on such information also requires adoption of appropriate and effective control rules that utilise such information. Here, we draw attention to diverse HCR, including fishery-dependent examples that have been considered, tested or already adopted for fisheries management. Our intention is to stimulate ideas for HCR that are usable with, or adaptable to fishery-independent indicators.
\end{abstract}

Key words: HCR / Fishery management / Survey-based management strategies

\section{Introduction}

A control rule $(\mathrm{CR})$ represents a pre-agreed plan for adjusting management of a fish stock based on its perceived status. The rule may (1) control the exploitation rate, (2) require that a minimal portion of the stock escapes capture (e.g., to maintain a specified spawning stock size), (3) limit the maximum catch over a period (i.e. a "harvest control rule", HCR), or (4) be a mixture of these strategies (FAO 2001). Control rules may be simple or complex, may utilise model- or observation-based indicators of the status of the stock, and may also take into account uncertainties in the required estimates of stock status. Reference points are also part of the development of a CR and often serve as trigger points that initiate some kind of action described in the CR.

The steps followed to calculate total allowable catches (TAC) for a stock provide an example of a simple HCR. A stock assessment based on data collected regularly for commercial fisheries, such as quantities of fish landed, fishing effort, and perhaps other variables, is used to estimate the absolute quantities of fish in the stock and a rate of fishing mortality, $F$, that will allow the stock to maintain itself or recover from a low state. The TAC for the fishery in the coming year is then derived as a function of the estimated stock size and $F$.

\footnotetext{
${ }^{a}$ Corresponding author:

panayiota.apostolaki@cefas.co.uk
}

A well-known problem with TAC is that commercial fishery data may be inaccurate, possibly in part a consequence of the existence of the TAC itself which might provide an incentive for fishers to under-declare quantities landed. A review of the application of HCR on stocks that are assessed by ICES or are under United States jurisdiction also showed that the uncertainty in the information that is often used in stock assessment is such that the results of the assessments are not informative enough to support the calculation of reference points used in HCR for a considerable number of those species (Cadrin and Pastoors 2008). Uncertainty/bias in the catch and other fisherydependent data used in stock assessment is one of the factors that contribute to the uncertainty in stock assessment results.

The idea of fishery-independent HCR has arisen because of these problems. Survey-based stock assessments have the potential to reduce bias associated with fishery-dependent data since they replace those data with data from surveys (use of information from surveys to validate the fishery dependent data and define the weight they will assign to them is another potential use of survey data but we will not touch on this here). Indicators of the status of a stock are derived from standardised fish surveys, commonly trawl surveys repeated annually. The indicators may be abundance indices related to catch per unit of effort (cpue), estimates of total mortality rate, $Z$, or they may be qualitative measures of fish size, growth, reproduction, etc. as discussed elsewhere in this volume (Cotter et al. 2009). 
None of these types of indicators provide absolute estimates of stock size. Therefore, an absolute TAC suitable for managing exploitation of the stock in following years cannot be derived. In this context, HCR derived from survey data are expected to provide information on future exploitation (e.g. TAC) only in relative terms. In this case, and if past TAC cannot be utilised in some way to inform the adoption of new catch quotas, there will necessarily be a period of adaptive management (Walters 1986) during which the level of response of the stock to given levels of harvesting is estimated. Despite these shortcomings, this type of CR (survey-based HCR) has the potential to provide an alternative solution to the management of exploitation of stocks for when either catch information does not exist or is not acceptable. For this reason, we have chosen to focus mainly on HCR that can support the development of surveybased HCR. Readers interested in exploring a wider range of CR could refer to Deroba and Bence (2008) and other papers mentioned in the next section.

Management strategies that use only survey-based HCR had not received much attention until recently. In the last few years this has changed; however, published articles on this topic are still scarce (but relevant discussions can be found, for example, in reports from stock assessment ICES workshops). Here, we draw attention to diverse HCR, using fisherydependent examples that have been considered, tested or already adopted for the management of specific fisheries. Our intention is to stimulate ideas for HCR that are usable with, or adaptable to fishery-independent indicators. We also draw attention to the different components of a HCR as well as their significance and contribution to the performance of the rules to facilitate development of effective management plans.

\section{Examples of harvest control rules from around the world}

Breen et al. (2003) provide a comprehensive list of the HCR that can be found in the literature, ranging from very simple to highly sophisticated. Such rules have been considered for the management of fisheries for more than two decades (see for example Quinn and Deriso 1999) and harvesting strategies have been developed for a number of marine species around the world. However, the case-specific development and application of HCR has not been straightforward for a number of reasons including the difficulties in translating management objectives and interests into quantitative terms that can be incorporated into the analysis, and the uncertainty in the results of relevant studies that complicate the process of defining an optimal harvesting policy (Parma 2002). This is one of the reasons why the management of fisheries for several fish stocks does not have formal HCR and does not follow predetermined actions to be taken when the conditions set by the harvest strategy are not met. Another possible reason is that the adoption of any management strategy requires a thorough (and often, very time consuming) evaluation of the relative performance of a wide range of possible HCR formulations against objectives set for the fishery and risks that stakeholders are prepared to take.

There is a growing body of research on the use of HRC as part of a management strategy plan, especially, on how to overcome difficulties associated with the uncertainty in understanding the system of interest, with several studies focusing on the methods that can be used for evaluating fishery management strategies and the problems and benefits of using those methods (Ruppert et al. 1984; Cooke 1999; Kell et al. 1999; Sainsbury et al. 2000; Deroba and Bence 2008; Haltuch et al. 2008; Punt et al. 2008). Some studies have also focused on the effectiveness of model-free as well as model-based HCR (Punt and Smith 1999; Breen et al. 2003) in the context of identifying strengths and weaknesses of HCR and determine an optimum way to utilise them. Below, we present examples of real applications of HCR for the management of marine species. We have chosen cases we feel are representative of the diversity of HCR considered worldwide and include elements that can be useful in building survey-based HCR.

\subsection{Management of exploitation of US West Coast groundfish stocks - The default maximum sustainable yield control rule}

Harvest control rules proposed by the different US regional Fisheries Management Councils and the National Marine Fisheries Service (NMFS) and adopted by the US government need to be in accordance with the national standards set by the Magnuson-Stevens Fishery Conservation and Management Act (often called the Magnuson-Stevens Act). The Act calls for management measures that will prevent overfishing while achieving the so-called "optimum yield" (National Standard 1). The optimum yield is used as a target when HCR are adopted for US stock. Although the Magnuson-Stevens Act constrains optimum yield to be no greater than the maximum sustainable yield (MSY), it does not provide detailed guidelines on how to find the optimum yield, or about the path to recovery and how to achieve optimum yield when populations have been over-exploited. To address this, technical guidelines have been prepared by scientists from the NMFS to help stock assessment scientists implement National Standard 1 (Restrepo et al. 1998).

The guidelines provide sets of HCR that can be used to specify management actions depending on the condition of the stock and the information available. They also provide guidance for specifying the "MSY control rule" which defines how the fishing mortality rate, $F$, used to calculate maximum allowable annual catches, should vary depending on the status of the stock:

$$
\begin{array}{ll}
F(B)=\frac{F_{\mathrm{MSY}} B}{c \cdot B_{\mathrm{MSY}}} & \text { for } B \leqslant c \cdot B_{\mathrm{MSY}} \\
F(B)=F_{\mathrm{MSY}} & \text { for } B>c \cdot B_{\mathrm{MSY}}
\end{array}
$$

where $F_{\mathrm{MSY}}$ is the fishing mortality rate that corresponds to maximum sustainable yield (MSY), $B$ is the stock biomass and $B_{\mathrm{MSY}}$ is the equilibrium biomass when the fishing rate is set equal to $F_{\text {MSY }} c$ is a constant equal to $\max (1-M, 0.5)$ where $M$ is the natural mortality rate. Thus, any decline of the stock biomass below the specified reference point $\left(c \cdot B_{\mathrm{MSY}}\right)$ will lead to the same decrease in the allowable fishing effort. An important characteristic of this rule is that it permits depletion 


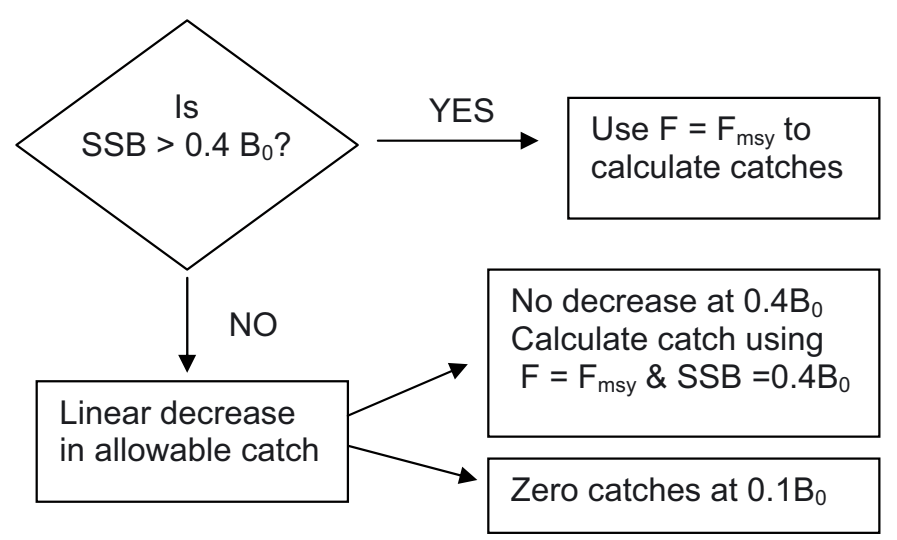

Fig. 1. Schematic representation of the HCR applied for the management of the groundfish fishery in the West Coast of USA. See text for an explanation of the symbols.

of the population to a size which is smaller than $B_{\mathrm{MSY}}$. According to this rule the population size can be reduced to as low as $50 \%$ of the corresponding $B_{\mathrm{MSY}}$ before a reduction of $F$ to values smaller than $F_{\mathrm{MSY}}$ is required. This means that, for a population with size less that $B_{\mathrm{MSY}}$, consecutive years of stock size reduction will not be enough to trigger reduction in fishing mortality. However, they will lead to smaller allowable catches.

The technical guidelines describe proxies for MSY, $F_{\mathrm{MSY}}$, etc. that can be used when there are not enough data to calculate those values. They also recommend a CR for data-poor cases. According to it, catches that can be used as an upper limit can be found using the average catch from a period when there was no evidence of declining abundance, together with best qualitative estimates of the current relative stock size:

Limit catch $=1.00 \times($ Recent catch $)$ when Stock size $>B_{\mathrm{MSY}}$ Limit catch $=0.67 \times($ Recent catch $)$ when $B_{\mathrm{MSY}}>$ Stock size $>$ MSST

Limit catch $=0.33 \times($ Recent catch $)$ when Stock size $<$ MSST

where MSST is the minimum stock size threshold below which the stock is considered overfished. The multipliers 1.0, 0.67, and 0.33 are based on the default precautionary target multipliers that the guidelines use to provide an interpretation of the "MSY control rule" for data-poor cases (Restrepo et al. 1998).

The management of the groundfish fishery in the West Coast of USA is a practical example of how the technical guidelines and the Magnuson-Stevens Act are implemented. The Pacific Fisheries Management Council has followed the concept described above (i.e. reduction of catches when the biomass decreases) to develop a " $40-10$ rule" that is applied for the management of ground fish stocks. The CR uses a proxy for $F_{\mathrm{MSY}}$ and the size of the spawning stock to define the allowable catches. If the spawning stock $(S S B)$ is above $40 \%$ of the unexploited spawning stock $\left(B_{0}\right)$ then the catches are calculated assuming $F=F_{\mathrm{MSY}}$. However, the catches are reduced if the spawning stock is below $40 \%$ of $B_{0}$. The reduction is linear starting from 0 at $0.4 B_{0}$ to become $100 \%$ at $0.1 B_{0}$ (Fig. 1).

The rule is applied only to stocks with spawning biomass greater than $25 \%$ of $B_{0}$. If the population is below that level then another procedure (rebuilding plan) will take precedence over the "40-10 rule". Therefore, this plan accepts that a simple rule can be appropriate to manage a population that is at a relatively healthy condition but is not enough when one deals with highly overexploited populations (see Punt 2003 for details on the rebuilding plan)

Although knowledge of the size of the population in absolute terms is needed to apply the above rule (i.e. to find the catches that correspond to $F_{\mathrm{MSY}}$ ), the rule can be used with relative abundance estimates if a good approximation of the catches that correspond to $F_{\text {MSY }}$ can be found using alternative methods (e.g. by examining the catches in past years to identify catch levels that did not cause population depletion, Dowling et al. 2008).

\subsection{Gemfish fishery in south-eastern Australia}

The exploitation of fisheries resources in Australia and the management of Australian fisheries are governed by the Fisheries Management Act (FMA). Among others, the FMA calls for optimum utilisation of living resources of the Australian fishing zone and adoption of proper conservation and management measures (through the adoption of fishery management plans) to ensure that the living resources in the Australian fishing zone are not endangered by over-exploitation. The management of the fishery for gemfish in south-eastern Australia is an example of the application of the Fisheries Management Act and adoption of HCR.

Punt and Smith (1999) describe the harvest strategy that was used to recommend a TAC for eastern gemfish. The harvest strategy uses three reference points; a target mature stock biomass $\left(M S B_{\min }\right)$ and an upper $\left(C_{\max }\right)$ and lower boundary $\left(C_{\min }\right)$ for catches. Simulation modeling is used to describe the dynamics of the population and its current status and project the population twenty years forward from the last year for which catch data are available taking into account uncertainties in the estimation of stock status. Based on the outcome of the simulation future TAC are calculated as follows:

- if we set $C=C_{\min }$ for the next 20 years and our projections show that $M S B$ will fall below $M S B_{\min }$ in the next 20 years then next year's catch will be set equal to $C_{\min }: T A C=$ $C_{\min }$,

- if we set $C=C_{\max }$ for next year and equal to $C_{\min }$ for the following 19 years and our projections show that $M S B$ will remain above $M S B_{\min }$ in the next 20 years then next year's $T A C$ can be set equal to $C_{\max }: T A C=C_{\max }$,

- if the catch can be set above $C_{\min }$ but not as high as $C_{\max }$ (option (2) is not met) then the catch for the following year is chosen such that $C_{\min }<C<C_{\max }$. If we set $T A C=C$ for next year and equal to $C_{\min }$ for the following 19 years and the projections show that $M S B$ will remain above $M S B_{\min }$ in the next 20 years then the $T A C$ for next year can be set equal to $C: T A C=C$.

This is an intricate, model-based HCR which also allows the use of past experience or observations to set the minimum acceptable size of the stock. If biomass and annual catches can be expressed in relative terms then the rule can also be applied to cases in which only the relative size of the stock is known. 


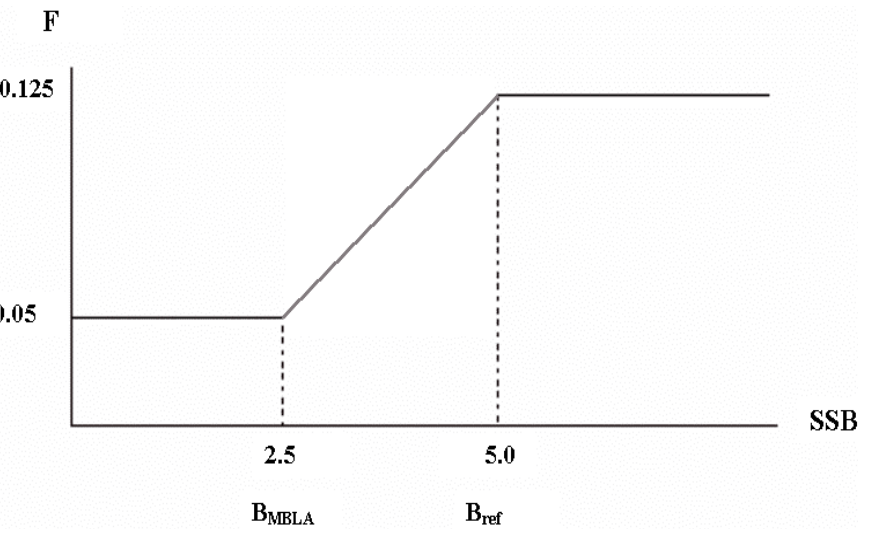

Fig. 2. Schematic representation of the HCR for managing exploitation of Norwegian spring-spawning herring. $F$ is the fishing mortality rate (Rottingen 2003). Biomass is expressed in metric tonne.

\subsection{Norwegian spring spawning herring and Northeast Arctic haddock}

An example of harvest rules which have been implemented and followed in practice in Europe are the rules applied for the management of Norwegian spring spawning herring and Northeast Arctic haddock.

The HCR for Norwegian spring spawning herring was adopted in 2001 and aims to keep the risk that the spawning biomass will fall below a pre-specified, minimum biologically acceptable level of biomass (denoted $B_{\mathrm{MBAL}}$ ) at low levels. To do so, it seeks to maintain the spawning biomass above a biomass level, $B_{\text {ref, }}$ which is higher than the $B_{\text {MBAL }}$. The value of $B_{\text {ref }}$ chosen for this stock is twice the value of $B_{\mathrm{MBAL}}$. If biomass falls below $B_{\text {ref }}$, the rule indicates that a linear reduction of fishing mortality rate should be introduced (Fig. 2).

The potential of this HCR to achieve recovery of the population has not yet been tested in practice because the population has not dropped below the $B_{\text {ref }}$ limit since the mid-90s when a long-term management plan was adopted for this stock (ICES 2007). However, the lower value of the fishing mortality to be adopted when the population approaches $B_{\mathrm{MBAL}}$ has been used in the past successfully to rebuild the population (Rottingen 2003; ICES 2007).

Knowledge of MSY or $F_{\text {MSY }}$ (or similar reference points) is not necessary to apply this rule. Further, the reference biomass that triggers management changes, $B_{\text {ref }}$, can be expressed relative to $B_{\mathrm{MBAL}}$. Thus, the rule can be applied in cases in which changes in stock biomass (or abundance in general) can only be predicted relatively to a reference value. Therefore, it is suitable for use with stock assessment methods, such as survey-based methods, that only provide relative information about stock status from year to year.

A similar CR to the one above which is also part of a management plan that has been tested to evaluate whether it is in agreement with the precautionary approach is the HCR for Northeast Arctic haddock (Needle 2008). According to this rule, the fishing mortality remains constant and equal to an agreed value as far as the stock biomass remains above a prespecified size. If the stock falls below that size the fishing mortality will be decreased by the same percentage as the decrease in stock size relative to the pre-specified stock size. The other HCRs we discussed so far do not explicitly determine what is the level of interannual variation in catches that the HCR can result in that is acceptable. The HCR for Northeast Arctic haddock does so; it does not permit changes in TAC of more than $\pm 25 \%$ of the previous year's TAC.

However, as in the case of the groundfish fishery in the West Coast of USA, this restriction is lifted if the size of the population has fallen below the pre-specified stock size used to define what the fishing mortality for the following year should be. This means that for overexploited population the need to maintain the population at a safe stock size takes precedence over the management objective of maintaining year-to-year stability in yield.

\subsection{Management of Patagonian toothfish fishery in the Antarctic}

A HCR for the adoption of precautionary catch limits for exploitation of toothfish (Patagonian and Antarctic) stocks in the Antarctic was adopted by the commission for the conservation of Antarctic marine living resources (CCAMLR) in 1994. It requires catch $(c)$ to be set conditional on target and limit reference points based on an estimate of the pre-exploitation spawner biomass $\left(B_{0}\right)$. The rule has three parts and uses model-based predictions about the future status of the population to provide estimates of sustainable catch (Constable et al. 2000):

- choose $c_{1}$, so that the probability of the spawning biomass dropping below $20 \%$ of its pre-exploitation median level over a 35 -year harvesting period is $10 \%$;

- choose $c_{2}$, so that the median toothfish escapement (i.e. that exists post-exploitation) in the spawning biomass over a 35 -year period is $50 \%$ of the pre-exploitation median level; and

- select the lower of $c_{1}$ and $c_{2}$ as the level for calculation of toothfish yield.

A similar approach was also applied for the management of the krill fishery, but here the projection period is 20 years and the escapement level is $75 \%$ of the median pre-exploitation spawning biomass to account for krill being a primary prey species. The interesting feature in the case of the toothfish stock is that catch data for that fishery were, historically, limited, and fishery-independent surveys for the adult part of the population do not exist (Constable et al. 2000). As a result, estimates of the pre-exploitation biomass and sustainable yield relative to it were not available. To overcome the problem, scientists used absolute estimates (based upon swept-area and density information) of recruit abundance available from surveys on the juvenile component of the population, and relative abundance indices to predict the long-term sustainable yield following the HCR described above. To do so, they used the recruit time series as an input to a population modelling package which projects forward in time the recruitment estimates from the survey. The use of absolute estimates of abundance of recruits also enables catches to be used in absolute terms and allows for the estimation of the long-term sustainable yield in biomass rather than as a relative value. 
More recently, mark-recapture data has allowed the construction of integrated assessments for toothfish fisheries in the CCAMLR convention zone (Hillary et al. 2006) and the absolute recruitment estimates are no longer applied to calculate a long-term yield in this manner but relative recruitment surveys are still vital in giving information on the most recent yearclasses (which are missing in the commercial data) which, in turn, influences the resultant long-term yield estimates. The rule with which long-term catches are calculated remains the same (as described above) but the assessment and projection models are now the same. This serves as a useful example of why the HCR and the management procedure are not the same entity - here the management procedure changed (the assessment method changed) but the HCR did not.

\section{Methods}

\subsection{Harvest control rules in the context of survey- based information and stock assessments}

As mentioned earlier, survey-based assessments can often only estimate the size of the population in relative, not absolute terms or give us total mortality estimates (unless we wish to assume that we know natural mortality and attempt a separation). This means that some of the reference points we mentioned earlier can be expressed only in relative terms. That can restrict the choice of HCR. The choice also depends on the objectives of the management plan. Below, we provide some ideas about components of HCR that could be part of a surveybased management plan and discuss how the main concept of HCR fits with the use of fishery independent data. Building on some of the concepts used in the HCR we presented above, we first express the management paradigm in a general way taking into account the information available from survey data and assessments conducted on survey data only. Then we use a reference species to provide an explanatory example and illustrate the effects of different features of a survey-based HCR on its response to changes in the values of relevant indices.

\subsection{A generic structure for setting harvest control rules}

Although the focus of this paper is on HCR using survey data-derived information the general idea of what HCR are and what type of information they can use is the same for rules that use only survey data, only commercial data or a mixture of the two. In terms of the available information and key variables one might have we consider the following:

- A set of measured indicators of the stock itself and the environment and ecosystem within which it resides: $I=$ $\left\{I_{1}, \ldots, I_{k}\right\}$. Some potential indicators could be the trend in mature/immature/exploitable stock biomass (either directly measured from survey data or from a stock assessment), mean weight, recruitment, total mortality, seasurface temperature, and so on.

- A set of reference and/or target points (absolute/relative) for use with the indicator set in assessing general "status": $R=\left\{R_{1}, \ldots, R_{l}\right\}$. Reference points could be related
Future SSB

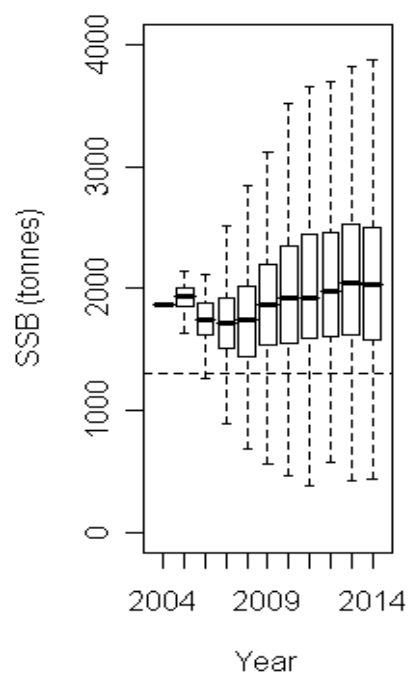

Future catch

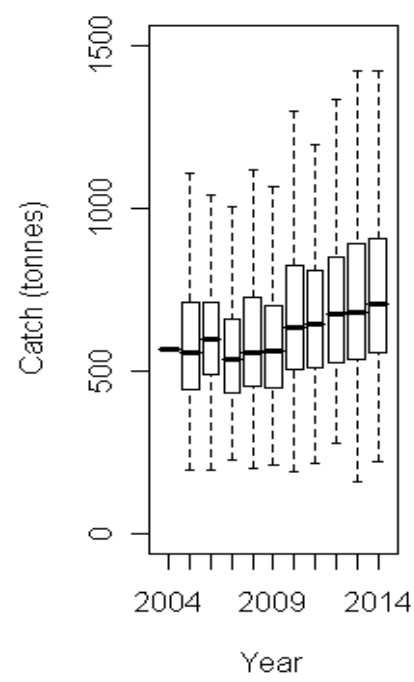

Fig. 3. Simple summary of the $N_{S S B}=1, N_{T A C}=2$ scenarios. On the right we have a box and whisker plot of the future herring $S S B$ (with the current agreed precautionary level $B_{P A}=1300 \mathrm{t}$ displayed as the horizontal dotted line) and on the left a box and whisker plot of the future herring catches as set by the HCR.

to abundance levels, total mortality, mean weight, or primary production levels.

- A set of auxiliary information about the stock and fishery of interest such as life-history information, economic parameters and constraints, trophic dependencies and so on: $A=\left\{A_{1}, \ldots, A_{m}\right\}$.

- A set of parameters, $\theta$, that can be used to mathematically define the HCR.

- The previous harvest actions: $H=\left\{H_{1}, \ldots, H_{n}\right\}$. These harvest actions cover any possible fishery actions such as catches, effort, capacity, mesh regulations and so on.

We can now express the dependence of a HCR, $F$, to the components described above in the following way:

$$
H_{t}=F\left(I, R, A, \theta, H_{\text {past }}\right) .
$$

The expression $H_{\text {past }}$ refers to all the harvest actions that occurred before time $t$, i.e. the full set of historical harvest actions.

So at any given time step $t$ the action of the HCR basically takes the relevant information from the indicators, references points, auxiliary information, and historical harvest set (for adaptive management) and defines a new harvest state (TAC, effort level, capacity level etc.). To perhaps better understand the role of the HCR parameters, $\theta$, it helps to consider their role in the management strategy evaluation process. It is usually (potentially a subset of) these parameters we attempt to estimate in some way, assuming the structure of the HCR to be fixed, given how they help achieve the management objectives.

To demonstrate a simple example of a survey-based HCR and highlight necessary considerations when constructing and applying such rules, we use the FLR set of tools (Hillary 2009) to explore the process of construction and evaluation of a simple set of candidate HCR. We use a reference species (North 
Sea herring) for our example to provide a real application of the example HCR.

To keep the example simple, we will use a model-free framework (no stock assessment method) and only biomass survey indices as our indicator set. We assume that we have a yearly relative $S S B$ survey index $I_{t}^{S S B}$ but the CV for the observation error is known (preferably for each year). Management is effected via an annual $T A C$ which is adapted year to year based upon temporal trends in the observed $S S B$ series. For the purpose of this example, we assume that the new TAC is set as an adjusted back-average of previous TAC. The adjustment is achieved through a multiplicative factor that indicates the (weighted) time-averaged growth in the survey SSB index:

$$
T A C_{t+1}=\left(\frac{1}{N_{T A C}} \sum_{i=t-N_{T A C}+1}^{t} T A C_{i}\right) \alpha_{t},
$$

where $N_{T A C}$ is the number of years over which we average previous $T A C$, and the TAC adjustment, $\alpha_{t}$, is defined as

$$
\alpha_{t}=\sum_{i=t-N_{S S B}+1}^{t} \omega_{i}\left(\frac{I_{i}^{S S B}}{I_{i-1}^{S S B}}\right),
$$

$N_{S S B}$ denotes the number of years over which we average the crude $S S B$ growth/decline trend. The weightings, $\omega_{t}$, sum to one and can be calculated in various ways as explained further below. If the survey index of the spawning stock has been consistently increasing/decreasing then the TAC will increase/decrease. The HCR as defined in Eqs. (2) and (3) allows us to set the values for, $N_{T A C}, ; \mathrm{t} ; N_{S S B} ;$ and also decide on what weight, $\omega_{t}$, to give to the historical $S S B$ growth/decline trends. It is worth explaining where each element fits in the generic framework we previously defined at the beginning of the section:

- $N_{T A C}$ : this can aid in controlling inter-annual variation in $T A C$ - the larger this value the more "memory" there is in the TAC time series reducing variation about the mean. It could potentially be a parameter of the HCR, $\theta$, to be estimated given the management objectives or part of the auxiliary information, $A$, where a previous study has already estimated useful/optimal values for a similar situation.

- $N_{S S B}$ : this could either be a parameter of the HCR or something derived from the auxiliary information, $A$. One can imagine that life-history information would be ideal information with which to establish sensible values. For a squid, with an approximate 1 year lifespan and subject to high stochastic abundance fluctuation, it would not seem sensible to use anything other than $N_{S S B}=1$; for a longer-lived more gradually maturing species it would be prudent to allow for potential increases in $N_{S S B}$, subject to information on year-class variability and productivity.

- $\omega_{t}$ : the relative weighting of the trend information could again be estimated (with likely constraints required to avoid confounding) as an HCR parameter or be informed by the auxiliary information. For example, with a survey where the precision varies strongly from year to year such a weighting based on relative precision would seem plausible.
Table 1. Summary table for the example HCR defined in Eq. (2). Here $B_{\text {fin }}$ and $C_{\text {fin }}$ are the final year (2014) spawner biomass and catch levels with $E\left(B_{\text {fut }}\right)$ and $E\left(C_{\text {fut }}\right)$ being the year-averaged future levels of spawner biomass and catch. Finally, $\Delta_{y}$ is the year-to-year fractional change in future TAC level. $N_{T A C}$ is the number of years over which we average previous $T A C$.

\begin{tabular}{lcccc}
\hline & \multicolumn{2}{c}{$N_{T A C}=1$} & \multicolumn{2}{c}{$N_{T A C}=2$} \\
\cline { 2 - 5 } & $N_{S S B}=1$ & $N_{S S B}=2$ & $N_{S S B}=1$ & $N_{S S B}=2$ \\
\hline$p\left(B_{\text {fin }}>B_{2004}\right)$ & 0.66 & 0.27 & 0.58 & 0.43 \\
$p\left(E\left(B_{\text {fut }}\right)>B_{2004}\right.$ & 0.55 & 0.24 & 0.54 & 0.39 \\
$p\left(C_{\text {fin }}>C_{2004}\right)$ & 0.72 & 0.82 & 0.73 & 0.89 \\
$p\left(E\left(C_{\text {fut }}\right)>C_{2004}\right)$ & 0.79 & 0.96 & 0.85 & 0.94 \\
$p\left(\left|\Delta_{y}\right|<0.15\right)$ & 0.71 & 0.53 & 0.76 & 0.42 \\
\hline
\end{tabular}

Note that our reference set in this case is empty as the HCR operates purely on trend information - no biological reference points are employed.

We will use North Sea herring as the reference stock to apply this HCR. North Sea herring are a relatively fast maturing species (between age 2 and 3), with significant but not huge random variation in year-class strength. Given this auxiliary information, and for the sake of brevity, we look at two possible cases for our example survey-based HCR: $N_{T A C}=$ $N_{S S B}=1,2$ with $\omega_{t}=1 / N_{S S B}$ (we assume a fixed survey observation error $\mathrm{CV}$ of $25 \%$ ). Our operating model for North Sea herring makes use of an age-structured population model (including stochastic stock-recruit dynamics) and a simple observation error model simulating an (unbiased) survey of the spawning stock biomass each year with an observation error $\mathrm{CV}$ of $25 \%$. In terms of the status of the stock at the current (2004 was assumed the first year for the projections) and previous recent years, we simulated a situation in which SSB levels are increasing quite rapidly from 2002 to 2004 but recruitment is weak. The full parameterization of the model is detailed in Hillary (2009). Given the 10 year life-span of North Sea herring the management simulation was run for 10 years with an assumed perfect implementation model, in that the $T A C$ was taken exactly each year.

\section{Results}

For our simple stock and fishery performance metrics, and given our Monte Carlo simulation framework, we use the probabilities that the final and year-averaged future spawner biomass and catch are greater than those observed at the beginning of the management simulation in 2004 as our performance metrics. A secondary fishery indicator is the probability with which the percentage change in future TAC from one year to the next is less than $15 \%$ - we use $15 \%$ as this appears to be a fairly consistent preferred industry option. A summary of the results of the management simulations (for the 4 possible scenarios) can be found in Table 1. A simple stock and fishery summary plot of the $N_{S S B}=1, N_{T A C}=2$ scenario is shown in Figure 1.

Using a multi-year indicator of stock status $\left(N_{S S B}=2\right)$ versus a simple year-to-year index $\left(N_{S S B}=1\right)$ seemed to increase the chance of depleting the future spawning stock biomass (Table 1). This occurred because the HCR acted to increase 
catches well above 2004 levels. When using only a two-year $\left(N_{S S B}=1\right) S S B$ trend - for either TAC back-averaging scenario - we appear to increase both SSB and TAC from 2004 levels with probability $>0.5$ (for either increase metric). The $N_{S S B}=2$ scenarios seem to effect a stock decline over the management period for the following three reasons:

- The rapid increase in SSB from 2002 to 2004 (20\%) results in successively larger TAC levels being set in 2005 and 2006.

- Even though weak year-classes in 2003 and 2004 decrease the SSB slightly in 2006-2008 the smoothing effect of the $\mathrm{HCR}$ in this case does not cause as significant a reduction in $T A C$ in this period as in the $N_{S S B}=1$ case.

- As the larger predicted future year-classes (SSB level is at the level that still yields maximum deterministic recruitment) come into the mature stock (which stabilizes in terms of trend) the TAC stays at this higher level and does not decrease sufficiently after 10 years to effect an increase in spawner biomass from 2004 levels.

These results provide a flavour of the role that different components of a HCR could play. Although we used only TAC as our harvest component, it could just as easily have been fishing effort (whatever this is defined to be) that was altered year-toyear in the HCR. We also employed only a single $S S B$ trend which was used to adjust yearly TAC levels and used simple probabilistic stock and fishery metrics to assess performance. Combination of indices can be used instead but, in that case, a more careful consideration of the significance that one will place on each of them is needed. Generally, there is scope for a huge number of potential HCR based on survey data. However, the simple example we used here allows us to separate the effects and contribution of key components of a HCR so they are easier to illustrate.

\section{Discussion}

Unreliable catch data, misreporting and biased catch per unit of effort indices have complicated the stock assessment of a considerable number of commercial fish species and, often, have thwarted the adoption of effective fishery management plans. On the other hand, scientists are increasingly asked to provide management advice for species which are either caught as by-catch or are indirectly affected by human activities and for which exploitation or biological information could be limited (Pilling et al. 2008). The development of stock assessment tools and HCR that rely on fishery-independent data could provide a way to address some of these problems.

Although the development of HCR and effort CR for use when stock parameters can only be estimated relatively is a fairly new area of research, it can build on and benefit from existing studies on fishery-dependent HCR and developments in the area of simulation modelling. In particular, simulation modelling tools, such as that used in FISBOAT to test fisherydependent or independent CR (M. Pomarede pers. comm.), can help scientists provide case-specific recommendations on survey design and identify combinations of survey, stock assessment and exploitation decision tools that would perform well under different conditions. Extensive work on the role of fishermen and society in general in the development and implementation of management plans (Nielsen et al. 2004; Cox and Kronlund 2008) can also be very useful in building robust HCR and management plans and designing appropriate monitoring programs.

The example we chose to outline here was very simple in nature but it helps us identify some key features of HCR. Also, it did not depend on complex biological or fishery reference points, which can be hard to estimate - especially in data-poor cases. Our results indicated that the memory that we build into our HCR (i.e. using a multi-year indicator instead of single year one) can have a great impact on the performance of the HCR. The way that we choose to link changes in the indicator to future TAC (adjustment parameters) is also a key feature of the rule and can determine how precautionary the CR is. One issue that we did not discuss here is about the role implementation time (time lag between the time the HCR is applied and the time when the corresponding management measures is implemented) plays in the development of HCR. We chose not to explore that aspect here mainly because of the complexity of such discussion, which can include issues such as accuracy of implementation, accounting correctly for the time lag in the HCR, the purpose of management feedback, etc., but also because this topic has been the focus of other published work (Kell et al. 2005; Loehle 2006).

Depending on the type and nature of the survey data available it is easy to envisage rules that are much more complex than the one we used in our calculations; they could include multiple indices of biomass, total mortality, mean length or environmental indices. Our examples of HCR used around the world provided a glimpse of such a potential. Survey data potentially offer as rich an array of available indicator information as conventional stock-assessment derived information perhaps more so if we consider that for a beam-trawl type survey information on not just the target species but potentially on other trophically-related species are collected together by the same design.

We do not mean to suggest here that management plans that depend only on survey data do not have limitations. Actually, a very obvious limitation is that they cannot use HCR that require quantities such as MSY or stock size in absolute terms. Some of the HCR presented here, and many of the rules currently in use, utilise such quantities to advise on future harvests. Further, the use of approaches that rely only on information on stock status that are in relative terms might mean that advice on effort levels only, rather than on TAC, might be available ${ }^{1}$ (unless some absolute estimates of stock status are available and can be used as a reference). Given the concerns expressed about the value of reference points and CR that use parameters such as MSY and unexploited stock size (Parma 2002) and problems with fishery-dependent data (concerns about accuracy, whether they can provide info about discarding, etc.), these limitations should not constrain the application of survey-based HCR. Instead, they could be seen as an opportunity to look for HCR that can reduce the dependency of management plans on data, assumptions, and reference points that are difficult to define.

1 In this case, effort limits, adopted based on effort control rules, could be used to manage the fishery. 
Acknowledgements. This research was undertaken as part of the EU funded project FISBOAT and the Defra funded project Risk Analysis for Fisheries. We would like to thank John Cotter for his valuable observations and comments. Laurence Kell, and Marine Pomarede also provided comments on an earlier version of the paper.

\section{References}

Breen P.A., Kim S.W, Bentley N., Starr P.J., 2003, Preliminary evaluation of maintenance management procedures for New Zealand rock lobster (Jasus edwardsii) fisheries. New Zealand Fisheries Assessment Report 2003/20, 65p.

Cadrin S.X., Pastoors M.A., 2008, Precautionary harvest policies and the uncertainty paradox. Fish. Res. 94, 367-372

Cooke J.G., 1999, Improvement of fishery-management advice through simulation testing of harvest algorithms. ICES J. Mar. Sci. 56, 797-810.

Constable A.J., de la Mare W.K., Agnew D.J., Everson I., Miller D., 2000, Managing fisheries to conserve the Antarctic marine ecosystem: practical implementation of the Convention on the conservation of Antarctic marine living resources (CCAMLR). ICES J. Mar. Sci. 57, 778-791

Cotter J., Petitgas P., Abella A., Apostolaki P., Mesnil B., Politou C.Y., Rivoirard J., Rochet M.J., Spedicato M.T., Trenkel V.M., Woillez M., 2009, Towards an ecosystem approach to fisheries management (EAFM) when trawl surveys provide the main source of information. Aquat. Living Resour. 22, 243-254.

Cox S.P., Kronlund A.R., 2008, Practical stakeholder-driven harvest policies for groundfish fisheries in British Columbia, Canada. Fish. Res. 94, 224-237.

Deroba J.J., Bence J.R., 2008, A review of harvest policies: Understanding relative performance of control rules. Fish. Res. 94, 210-223

Dowling N.A., Smith D.C., Knuckey I., Smith A.D.M, Domaschenz P., Patterson H.M., Whitelaw W., 2008, Developing harvest strategies for low-value and data-poor fisheries: Case studies from three Australian fisheries. Fish. Res. 94, 380-390.

FAO, 2001, Research implications of adopting the precautionary approach to management of tuna fisheries. FAO Fisheries Circular No. 963

Hillary R.M., Kirkwood G.P., Agnew D.J., 2006, An assessment of toothfish in subarea 48.3 using CASAL. CCAMLR Sci. 13, 6595.

Hillary R.M., 2009, An introduction to FLR fisheries simulation tools. Aquat. Living Resour. 22, 225-232.

Haltuch M.A., Punt A.E, Dorn M.W., 2008, Evaluating alternative estimators of fishery management reference points. Fish. Res. 94, 290-303

ICES, 2007, Report of the ICES Advisory Committee on Fishery Management, Advisory Committee on the Marine Environment and Advisory Committee on Ecosystems. ICES advice 2007, Book 9.

Kell L.T., O'Brien C.M., Smith M.T., Stokes T. K., Rackham B.D., 1999, An evaluation of management procedures for implementing a precautionary approach in the ICES context for North Sea plaice (Pleuronectes platessa). ICES J. Mar. Sci. 56, 834-845.
Kell L.T., Pastoors M.A., Scott R.D., Smith M.T., Van Beek F.A., O'Brien C.M., Pilling G.M., 2005, Evaluation of multiple management objectives for Northeast Atlantic flatfish stocks: Sustainability vs. stability of yield ICES J. Mar. Sci. 62, 11041117.

Loehle C., 2006, Control theory and the management of ecosystems. J. Appl. Ecol. 43, 957-966

Ludwig D., Hilborn R., 1983, Adaptive probing strategies for agestructured fish stocks. Can. J. Fish. Aquat. Sci. 40, 559-569.

Needle C.L., 2008, Management strategy evaluation for North Sea haddock. Fish. Res. 94, 141-150.

Nielsen J.R., Degnbol P., Viswanathan K.K., Ahmed M., Hara M., Abdullah N.M.R., 2004, Fisheries co-management-an institutional innovation? Lessons from South East Asia and Southern Africa. Mar. Policy 28, 151-160.

Parma A.M., 2002, In search of robust harvest rules for Pacific halibut in the face of uncertain assessments and decadal changes in productivity. Bull. Mar. Sci. 70, 423-453.

Pilling G.M., Apostolaki P., Failler P., Floros C., Large P.A., Morales-Nin B., Reglero P., Stergiou K.I., Tsikliras A.C., 2008, Assessment and management of data poor fisheries. In: Payne A.I.L., Cotter A.J.R., Potter T. (Eds.) Advances in Fisheries Science: 50 years on from Beverton and Holt. Blackwell Publishing.

Punt A.E., Smith A.D.M., 1999, Harvest strategy evaluation for the eastern stock of gemfish (Rexea solandri). ICES J. Mar. Sci. 56, 860-875.

Punt A.E., 2003, Managing West Coast groundfish resources through simulations. Fish. Bull. 101, 860-873.

Punt A.E, Dorn M.W, Haltuch M.A., 2008, Evaluation of threshold management strategies for groundfish off the U.S. West Coast. Fish. Res. 94, 251-266.

Quinn T.J. II, Deriso R.B., 1999, Quantitative Fish Dynamics. Oxford University Press, New York.

Restrepo V.R, Thompson G.G., Mace P.M., Gabriel W.L., Low L.L., MacCall A.D., Methot R.D., Powers J.E., Taylor B.L., Wade P.R., Witzig J.F., 1998, Technical guidance on the use of precautionary approaches to implementing national standard 1 of the Magnuson-Stevens fishery conservation and management act. NOAA Technical Memorandum NMFS-F/SPO-31.

Rottingen I., 2003, The agreed recovery plan in the management of Norwegian spring-spawning herring. ICES CM 2003/U:01

Ruppert D., Reish R.L., Deriso R.B., Carroll R.J., 1984, Optimization using stochastic approximation and Monte Carlo simulation (with application to harvesting of Atlantic menhaden). Biometrics 40, 535-545.

Sainsbury K.J., Punt A.E., Smith A.D.M., 2000, Design of operational management strategies for achieving fishery ecosystem objectives. ICES J. Mar. Sci. 57, 731-741.

Walters C., 1986, Adaptive management of renewable resources. MacMillan Publishing Co., New York.

WG-FSA, 2001, Report of the working group on fish stock assessment. Hobart, Australia. Commission for the conservation of Antarctic living marine resources. 